\title{
Evaluation of techniques of single continuous suturing in penetrating keratoplasty
}

\author{
Rasik B Vajpayee, Vidushi Sharma, Namrata Sharma, Anita Panda, Hugh R Taylor
}

\begin{abstract}
Aim-To evaluate the three techniques of single continuous suturing-namely, torque, antitorque, and no torque in penetrating keratoplasty.

Methods-53 eyes of 53 patients underwent penetrating keratoplasty using torque (17 patients), antitorque (18 patients), and no torque (18 patients) suturing techniques in this prospective study. Patients were followed up at 4 weeks, 3 months, and 6 months. Keratometric, videokeratographic, refractive astigmatism, and best corrected visual acuity were determined in all the three groups at each follow up visit. Post-keratoplasty suture adjustment was done at 4 weeks, if the astigmatism was $>3$ dioptres.
\end{abstract}

Results-The initial astigmatism in the torque group was higher than in the other two groups, although it was not statistically significant. Following suture adjustment, there was a significant decrease in astigmatism in all the three groups $(p<0.0001)$. However, no significant difference in the postoperative astigmatism at 3 months and at 6 months was seen among the three groups.

Conclusions-The three techniques of single continuous suturing-that is, torque, antitorque, and no torque produce a similar final astigmatic results. Suture adjustment is an effective method of reducing post-penetrating keratoplasty astigmatism.

(Br F Ophthalmol 2001;85:134-138)

Dr Rajendra Prasad Centre For

Ophthalmic Sciences, All India Institute of

Medical Sciences, New Delhi, India

R B Vajpayee

V Sharma

N Sharma

A Panda

Centre For Eye

Research, Melbourne,

Australia

H R Taylor

Correspondence to: Rasik B Vajpayee, D Rajendra Prasad Centre for

Ophthalmic Sciences, All

India Institute of Medical

Sciences, New Delhi 110029 ,

India

rbvajpay@hotmail.com

Accepted for publication 11 September 2000 improper suture placement, unequal suture tension, and irregular wound healing. ${ }^{1}$ Among the various suturing techniques, single continuous suture has been shown to be better than either interrupted suturing or combined continuous and interrupted suturing in terms of postoperative astigmatism..$^{2-5}$

To the best of our knowledge, there is no published clinical study to date to compare the three types of single continuous suturing techniques-namely, torque, antitorque, and no torque.
Materials and methods

Fifty three eyes (of 53 patients) undergoing optical penetrating keratoplasty were enrolled in the study through the cornea clinic of $\mathrm{Dr}$ Rajendra Prasad Centre for Ophthalmic Sciences between March 1996 and October 1997. Patients less than 12 years of age or with coexistent ocular pathology were excluded. In our routine protocol we do not apply continuous sutures in cases of vascularised corneas and the same was followed for this study. Cases of corneoiridic scars had minimal vascularisation and only those cases in which the vascularisation was present in less than one quadrant were enrolled in the study.

The eyes included in the study were randomly assigned to three different groups of single continuous suturing-torque, antitorque, and no torque (Fig 1). For the purpose of this study the term "antitorque" was defined as a single running suture which induces a torque, but in a direction opposite to a conventional radial/oblique suture. The most common indication for penetrating keratoplasty in all the three groups was a corneal opacity (sec-

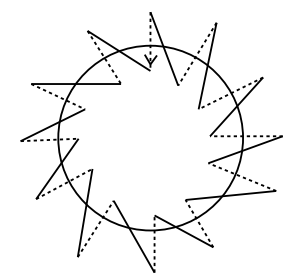

Torque pattern of single continuous suturing

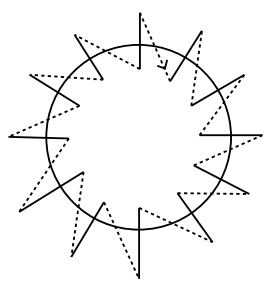

Antitorque pattern of single continuous suturing
No torque pattern of single continuous suturing Figure 1 Three types of continuous suturing techniques. 
Table 1 Indications for penetrating keratoplasty

\begin{tabular}{lccc}
\hline Indication & Torque & Antitorque & No torque \\
\hline Corneal scar & 11 & 10 & 11 \\
Pseudophakic bullous keratopathy & 2 & 3 & 3 \\
Failed graft & 1 & 1 & 2 \\
Aphakic bullous keratopathy & 2 & 1 & 1 \\
Macular corneal dystrophy & 1 & 1 & 1 \\
Congenital hereditary endothelial dystrophy & 0 & 1 & 0 \\
Bullous keratopathy after trauma & 1 & 0 & 0 \\
\hline
\end{tabular}

$\chi^{2}=5.29, \mathrm{df}=12, \mathrm{p}$ value $=0.95$.

ondary to healed corneal ulcer or trauma), followed by pseudophakic bullous keratopathy (Table 1). Out of 53 patients, 18 underwent antitorque single continuous suturing with oblique intrastromal bites and radial overlying sutures. Eighteen eyes underwent a no torque type of single continuous suturing with oblique intrastromal as well as overlying sutures, at equal inclination, and 17 underwent a torque type of single continuous suturing with radial intrastromal bites and oblique overlying sutures. $^{9}$

OPERATIVE TECHNIQUE

A single surgeon (RBV) performed all surgeries with local anaesthesia. Donor eyes preserved in McCarey Kaufman medium were used. All donor corneas were trephined on a paraffin wax block from the endothelial side upward using hand held trephines. Under the operating microscope the trephine centration was determined on the basis of pupillary axis for patients with a normal pupil and the anatomical centre for patients with pupillary abnormalities. The host cornea was marked with modified keratoplasty suture marker (Fig 2) using gentian violet. A hand held trephine (Storz Ophthalmics, St Louis, MI, USA ) was used to trephine the cornea up to $90 \%$ depth. The anterior chamber was entered with a blade braker and the corneal button was cut subsequently with a corneoscleral scissors leaving a slight posterior bevelling. In all the cases, the graft-host disparity was $0.5 \mathrm{~mm}$. The donor button was transferred onto the host cornea and four cardinal sutures were placed at $12,6,3$, and 9 o'clock positions. A single continuous suture was placed as described above for the three different types of suturing and the knot was tied superiorly and buried into the wound. No intraoperative keratometry was done. The four cardinal sutures were then removed and the running suture tightened to obtain wound apposition over 360 degrees. No

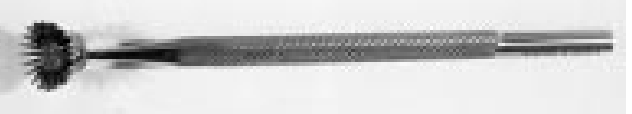

Figure 2 Modified keratoplasty suture marker. intraoperative suture adjustment was performed in any of the cases. Postoperatively, all patients received betamethasone-neosporin eye drops and artificial tears four times a day, which were subsequently tapered over 6 months.

Out of 53 patients enrolled, four were lost to follow up (two antitorque group, two torque group), three patients had graft failures (one antitorque group, two no torque group), and one developed post-penetrating keratoplasty glaucoma (no torque group) and were excluded from the statistical analysis.

The astigmatism was measured at 4 weeks, following each suture adjustment, at 3 months and at 6 months. Keratometry was done (Bausch \& Lomb, Rochester, NY, USA). Corneal topography was performed in all cases (Eye Sys Labs, Houston, TX, USA) and simulated keratometry readings were taken. The refractive cylinder was calculated and the best corrected visual acuity was recorded at each follow up visit.

All patients having astigmatism of more than 3 dioptres (D) at 4 weeks underwent suture adjustment. Under topical 4\% Xylocaine, patients were seated at the slit lamp. A jeweller's and a tying forceps were used to bring the extra length of the suture by pulling the suture from the flatter meridian to the steeper meridian of the cornea where suture tension was high. Special care was taken to grasp the suture at a 90 degree angle with the jaws of the forceps tangential to the corneal surface to minimise forces that might break the suture. A colour coded topographic map was used for this purpose. In case of a disparity between the keratometric, videokeratographic and refractive astigmatism, the refractive astigmatism was taken as a guide to decide about the need for suture adjustment. The wound was not disrupted during the adjustment, although the epithelium was debrided, if required, to gain access to the suture. Following suture adjustment, the frequency of the topical steroids was increased. Re-evaluation was done at 1 week following first suture adjustment; a second suture adjustment was undertaken if the astigmatism was more than $3 \mathrm{D}$ and further suture adjustment was possible. Optical stability was defined as a reduction in astigmatism to less than or equal to 3 dioptres or until further suture manipulation to reduce astigmatism was not possible. The $3 \mathrm{D}$ cut off was chosen because it was used in other series and facilitated the comparison with different studies. $^{5}$ The surgically induced refractive change due to suture adjustment was calculated using the method of Holladay et al. ${ }^{10}$

DATA ANALYSIS

Keratometric, topographic, and refractive astigmatism at 4 weeks, following first suture adjustment, at 3 months, and at 6 months were compared among the three groups using the one way AOV test (parametric and nonparametric, as applicable) for statistical significance. The percentage of patients requiring suture adjustment in each group was also compared. The change in astigmatism after suture 
adjustment in the three groups was compared (preadjustment and post-adjustment) using the paired $t$ test.

The $\chi^{2}$ test with Yates's correction was used to assess the uniformity in the preoperative diagnosis between the three groups.

\section{Results}

The mean age of the patients undergoing torque, antitorque, and no torque sutures was 44.06 (SD 18.01), 44.3 (15.27), and 44.6 (18.98) years respectively. Of 53 eyes, an optical penetrating keratoplasty alone was performed in 45 eyes, a triple procedure was done in five eyes, and a penetrating keratoplasty with intraocular lens exchange was undertaken in three eyes. All the three groups were matched with respect to the preoperative diagnosis $\left(\chi^{2}=\right.$ 5.29 and $\mathrm{df}=12$ ) with no difference between the groups $(p=0.95)$ (Table 1$)$.

The initial astigmatism measured at 4 weeks (before any suture adjustment) was higher in the torque group on keratometry, refraction as well as videokeratography (Tables $2,3,4$ ) although the statistical analysis did not achieve the conventional level of $\mathrm{p}=0.05 \quad \mathrm{p}=0.08$, $\mathrm{p}=0.06$ and $\mathrm{p}=0.08$ for keratometry, refraction, and videokeratography respectively). Out of 45 eyes, 30 had astigmatism of more than $3 \mathrm{D}$ and underwent suture adjustment (12 in the torque group, 11 in the antitorque group, and seven in the no torque group). Of these 30 eyes, four required a second suture adjustment (two in the torque group and two in the no torque group) and one eye in the torque group required a third suture adjustment. The proportion of patients requiring suture adjustment in each category did not show a statistically significant difference among the three groups $(p=0.12)$. The astigmatism measured after suture adjustments did not reveal any significant difference between the three groups and this remained so at the 3 month and 6 month follow up on keratometry, videokeratography, and refraction (Tables 2, 3, 4). Astigmatism was decreased in all the cases, irrespective of the magnitude of preadjustment astigmatism. The magnitude of preadjustment astigmatism varied widely, the maximum being $16.96 \mathrm{D}$, in the torque group as measured on videokeratography (Fig $3 \mathrm{~A}$ and $\mathrm{B}$ ). The average preadjustment astigmatism for 30 cases in which suture adjustment was done was 7.89 (SD 3.37) D, 7.21 (2.77) $\mathrm{D}$, and 7.71 (3.14) D on videokeratography, refraction, and keratometry respectively. The average postadjustment astigmatism following first suture adjustment decreased to 3.71 (1.9) $\mathrm{D}, 3.08$ (1.33) D, and 3.52 (1.47) D on videokeratography, refraction, and keratometry, respectively. On statistical analysis, the decrease in astigmatism after suture adjustment was found to be highly significant, $\mathrm{p}<0.0001$ using the paired $t$ test. The surgically induced refractive change due to suture adjustment according to the Holladay formula was 6.52 (4.56), 4.48 (2.03), and 5.73 (3.03) for the torque, antitorque, and no torque groups respectively with no statistically significant difference among the three groups $(\mathrm{p}=0.35)$ (Table 5$)$.

Second suture adjustment $(n=4)$, was done in only four cases and this could not be statistically analysed as the sample size was too small.

The change after suture adjustment was found to be stable during the study period. In the 30 patients requiring suture adjustment,

Table 2 Keratometric astigmatism

\begin{tabular}{llllll}
\hline & $K m 4$ & $K m S A_{1}$ & $K m S A_{2}$ & $K m 12$ & $K m 24$ \\
\hline Torque & $7.51(4.3)(\mathrm{n}=15)$ & $3.57(1.5)(\mathrm{n}=12)$ & $3.37(0.5)(\mathrm{n}=2)$ & $3.31(1.4)(\mathrm{n}=15)$ & $3.31(1.4)(\mathrm{n}=15)$ \\
Antitorque & $5.36(2.9)(\mathrm{n}=15)$ & $2.98(0.5)(\mathrm{n}=11)$ & & $3.31(1.8)(\mathrm{n}=15)$ & $3.92(1.9)(\mathrm{n}=15)$ \\
No torque & $4.54(3.8)(\mathrm{n}=15)$ & $4.32(2.2)(\mathrm{n}=7)$ & $3.06(0.4)(\mathrm{n}=2)$ & $2.86(1.5)(\mathrm{n}=15)$ & $3.22(1.8)(\mathrm{n}=15)$ \\
\hline
\end{tabular}

$\mathrm{Km} 4=$ keratometric astigmatism at 4 weeks.

$\mathrm{Km} \mathrm{SA} A_{1}=$ keratometric astigmatism after first suture adjustment.

$\mathrm{Km} \mathrm{SA}{ }_{2}=$ keratometric astigmatism after second suture adjustment.

$\mathrm{Km} 12=$ keratometric astigmatism at 12 weeks.

$\mathrm{Km} 24=$ keratometric astigmatism at 24 weeks.

Table 3 Videokeratographic astigmatism

\begin{tabular}{llllll}
\hline & $V K G 4$ & $V K G S A_{1}$ & $V K G S A_{2}$ & VKG 12 & $V K G 24$ \\
\hline Torque & $7.89(4.8)(\mathrm{n}=15)$ & $4.16(2.1)(\mathrm{n}=12)$ & $3.88(0.1)(\mathrm{n}=2)$ & $3.56(1.4)(\mathrm{n}=15)$ & $3.52(1.2)(\mathrm{n}=15)$ \\
Antitorque & $5.29(2.7)(\mathrm{n}=15)$ & $3.06(0.6)(\mathrm{n}=11)$ & & $3.35(1.7)(\mathrm{n}=15)$ & $3.63(1.9)(\mathrm{n}=15)$ \\
No torque & $4.67(3.8)(\mathrm{n}=15)$ & $3.97(2.8)(\mathrm{n}=7)$ & $2.66(0.1)(\mathrm{n}=2)$ & $2.86(1.2)(\mathrm{n}=15)$ & $3.28(1.6)(\mathrm{n}=15)$ \\
\hline
\end{tabular}

VKG $4=$ videokeratographic astigmatism at 4 weeks.

VKG SA $=$ videokeratographic astigmatism after 1st suture adjustment.

VKG SA = videokeratographic astigmatism after 2 nd suture adjustment.

VKG 12 = videokeratographic astigmatism at 12 weeks.

VKG $24=$ videokeratographic astigmatism at 24 weeks

Table 4 Refractive astigmatism

\begin{tabular}{llllll}
\hline & Ref 4 & Ref $S A_{1}$ & Ref $S A_{2}$ & Ref 12 & Ref 24 \\
\hline Torque & $7.03(4.1)(\mathrm{n}=15)$ & $3.38(1.4)(\mathrm{n}=12)$ & $3.5(0.7)(\mathrm{n}=2)$ & $3.13(1.2)(\mathrm{n}=15)$ & $3.13(1.2)(\mathrm{n}=15)$ \\
Antitorque & $4.97(2.3)(\mathrm{n}=15)$ & $2.54(0.5)(\mathrm{n}=11)$ & & $2.97(1.6)(\mathrm{n}=15)$ & $3.3(1.6)(\mathrm{n}=15)$ \\
No torque & $4.1(3.4)(\mathrm{n}=15)$ & $3.43(1.9)(\mathrm{n}=7)$ & $2.5(0.7)(\mathrm{n}=2)$ & $2.58(1.2)(\mathrm{n}=15)$ & $3.1(1.8)(\mathrm{n}=15)$ \\
\hline
\end{tabular}

Ref $4=$ refractive astigmatism at 4 weeks.

Ref $\mathrm{SA}_{1}=$ refractive astigmatism after 1 st suture adjustment.

Ref $\mathrm{SA}_{2}=$ refractive astigmatism after 2 nd suture adjustment.

Ref $12=$ refractive astigmatism at 12 weeks.

Ref $24=$ refractive astigmatism at 24 weeks. 


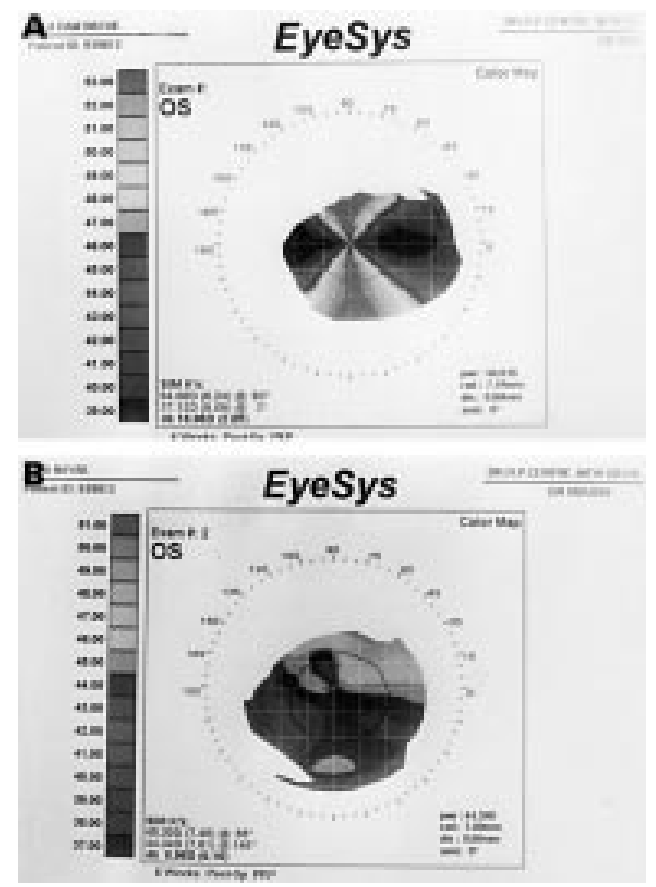

Figure 3 (A) Preadjustment videokeratography map of a patient in the torque group. (B) Post-adjustment videokeratography map of the same patient.

Table 5 Surgically induced refractive change due to first suture adjustment

\begin{tabular}{ll}
\hline & $\begin{array}{l}\text { Vector corrected change } \\
\text { in refractive astigmatism }\end{array}$ \\
\hline Torque & $6.52(4.56)$ \\
Antitorque & $4.6(2.18)$ \\
No torque & $6.56(2.84)$ \\
\hline
\end{tabular}

the average astigmatism changed from $3.71 \mathrm{D}$ $(1.9 \mathrm{D})$ to $3.15 \mathrm{D}(1.36 \mathrm{D})$ on videokeratography, from $3.08 \mathrm{D}(1.33 \mathrm{D})$ to $3.11 \mathrm{D}(1.21 \mathrm{D})$ on refraction, and from $3.52 \mathrm{D}(1.47 \mathrm{D})$ to $3.46 \mathrm{D}(1.47 \mathrm{D})$ on keratometry over a period of 2 months (measurements taken after suture adjustment and again at 3 months).

On comparing the astigmatism at 3 months with that at 6 months, no significant drift was found. The average astigmatism in 45 cases increased from 3.16 (1.54) D, 3.25 (1.46) D, and 2.89 (1.33) D on keratometry, videokeratography, and refraction respectively at 3 months, to 3.48 (1.73) D, 3.47 (1.60) D, and 3.17 (1.52) D at 6 months $(\mathrm{p}=0.13, \mathrm{p}=0.32$, and $\mathrm{p}=0.16$ for keratometry, videokeratography, and refraction respectively). The best corrected visual acuity was comparable in all three groups at each follow up visit (Table 6).

In one patient, excluded from the study, because of irregular follow up, the suture was found to be broken when the patient was examined at 3 months. This was possibly due to the earlier suture adjustment done at 4 weeks, which might have caused a weakening of the suture, ultimately leading to suture breakage. No wound dehiscence was noted. The suture end was cut flush with the cornea and buried. The patient did not return for a subsequent follow up.

\section{Discussion}

Single continuous suturing technique is associated with less final postoperative astigmatism compared with the interrupted suturing techniques as a result of even distribution provided by the single suture. Multiple interrupted sutures can disrupt the even distribution of corneal tension, thereby hindering astigmatism.

Single continuous suturing for penetrating keratoplasty became a preferred method of suturing, after McNeil and Wessels ${ }^{6}$ in 1989 first described the technique of suture adjustment to decrease the post-keratoplasty astigmatism. Subsequently, the advantage of postoperative suture adjustment of single continuous suturing was re-established in a randomised controlled trial by Lin et $a l^{2}$ in 1990 and in various other studies done subsequently. ${ }^{35}$

Yue-Kong-Au et al have recently reported their results on the observation of graft rotation in cadaver eyes where the three patterns of single continuous suturing - the torque, antitorque, and no torque were compared. They found that the torque pattern rotates the graft anticlockwise by $11^{\circ}$ or $0.7(0.1) \mathrm{mm}$ at the wound, the antitorque pattern rotates the graft clockwise by $11^{\circ}$ or $0.7(0.1) \mathrm{mm}$ at the wound, while the no torque pattern does not produce any rotational effect. However, to the best of our knowledge, there has been no clinical study to compare the different subgroups of single continuous suturing techniques.

It has been suggested that since the antitorque suturing has radial overlying sutures, there is no rotation of the anterior corneal surface thereby causing less astigmatism than the torque or the no torque suturing technique. ${ }^{9}$ The distortion in the antitorque suturing technique occurs more in the deeper layers of cornea and does not contribute much to corneal astigmatism postoperatively. With the torque suturing technique, the oblique overlying suture segment causes distortion of anterior corneal surface, thereby contributing to postpenetrating keratoplasty astigmatism. ${ }^{11}$ In the no torque single continuous suturing tech-

Table 6 Best corrected decimal visual acuity

\begin{tabular}{|c|c|c|c|c|c|}
\hline & $V N 4$ & $V N S A_{1}$ & $V N S A_{2}$ & $V N 12$ & $V N 24$ \\
\hline Torque & $0.19(0.11)(\mathrm{n}=15)$ & $0.23(0.06)(\mathrm{n}=12)$ & $0.28(0.04)(n=2)$ & $0.38(0.17)(\mathrm{n}=15)$ & $0.49(0.22)(\mathrm{n}=15)$ \\
\hline Antitorque & $0.23(0.1)(\mathrm{n}=15)$ & $0.33(0.18)(\mathrm{n}=11)$ & & $0.41(0.16)(\mathrm{n}=15)$ & $0.43(0.15)(n=15)$ \\
\hline No torque & $\begin{array}{l}0.18(0.1)(\mathrm{n}=15) \\
\mathrm{P}=0.47\end{array}$ & $\begin{array}{l}0.21(0.09)(\mathrm{n}=7) \\
\mathrm{P}=0.1\end{array}$ & $0.3(0.0)(\mathrm{n}=2)$ & $\begin{array}{l}0.29(0.12)(\mathrm{n}=15) \\
\mathrm{P}=0.08\end{array}$ & $\begin{array}{l}0.37(0.16)(n=15) \\
p=0.19\end{array}$ \\
\hline
\end{tabular}

VN4 = visual acuity at 4 weeks.

VN SA 1 = visual acuity after first suture adjustment.

VN SA 2 = visual acuity after second suture adjustment.

VN $12=$ visual acuity at 12 weeks.

VN $24=$ visual acuity at 24 weeks. 
nique since the intrastromal bites and the overlying sutures are at equal inclination, they act as a splint and cause less corneal distortion. ${ }^{9}{ }^{11}$ Our study corroborates the above suggestions and although the torque suturing technique showed the highest astigmatism, the difference between the three types of single continuous suturing techniques was not significantly different. It seems reasonable to assume that the torque group shows a substantially higher astigmatism than the other two groups, as in a larger group of patients this difference may become statistically significant. Our study highlights the fact that the torque technique of suturing may cause more astigmatism compared with antitorque and no torque suturing techniques in penetrating keratoplasty.

Single continuous suture offers the possibility of postoperative suture adjustment ${ }^{6-8}$ to decrease the astigmatism, which can be done earlier than the selective suture removal of interrupted suturing. Another advantage of a single continuous suturing technique is that its adjustment is reversible. Furthermore, it also decreases astigmatism with the suture still in place, thereby providing greater safety to the wound compared with the selective suture removal following interrupted suturing.

Suture adjustment effectively decreased the post-keratoplasty astigmatism in all three suturing techniques in our study irrespective of the magnitude of preadjustment astigmatism. Other authors have also shown similar results. Van Meter et a $\bar{l}$ showed a decrease from 6.5 (4.4) $\mathrm{D}$ to 1.5 (1.1) $\mathrm{D}$, Lin et al showed a decrease in astigmatism from 6.7 (2.3) D to $1.9(0.6) \mathrm{D}$ and Filatov $e t a l^{\beta}$ showed a decrease in astigmatism from 5.4 (3.7) D to 3.4 (2.4) D. A slightly higher astigmatism following suture adjustment can be attributed to the primary host pathology wherein most cases were corneal scars and possibly the result of the lack of use of an intraoperative keratometer.

Although the results of suture adjustment seem to be stable, a longer follow up of such patients is required, as there might be an increase in astigmatism over a period of time. Moreover all the sutures were in place at the time of final analysis. The astigmatic results in any suturing technique can only be optimally evaluated after all the sutures have been removed..$^{12} 13$

Potential complications during suture adjustments deserve mention. Sterile instruments should be used to manipulate the continuous suture. The risk of infection and perforation into the anterior chamber exists while manipulating the suture. Although one suture breakage occurred in our study it was successfully managed. Nevertheless, we recommend that only experienced corneal surgeons perform suture adjustment.

Presented as a poster at the American Academy of Ophthalmology, Annual Meeting, New Orleans, 1998.

1 Serdarevic ON. Refractive corneal transplantation: control of astigmatism and ametropia during penetrating keratoplasty. Int Ophthalmol Clinics 1994;34:13-33.

2 Lin DTC, Wilson SE, Reidy JJ, et al. An adjustable running uture technique to reduce post-keratoplasty astigmatism. A preliminary report. Ophthalmology 1990;97:934-8.

3 Filatov V, Steinert RF, Talamo JH. Post keratoplasty astigmatism with single running suture or interrupted sutures. Am f Ophthalmol 1993;115:715-21.

4 Eliason JA, McCulley JP. A comparison between interrupted and continuous suturing techniques in keratoplasty. Cornea 1990;9:10-16.

5 Van Meter WS, Gussler JR, Soloman KD, et al. Postkeratoplasty astigmatism control: single continuous suture pasty astigmatism control: single continuous suture adjustment versus selective inter

6 McNeil JI, Wessels IF. Adjustment of single continuous suture to control astigmatism after penetrating keratosuture to control astigmatism after pen
plasty. Refract Corneal Surg 1989;5:216-23.

7 Heider W, Ohrloff C. Long term stability of astigmatism after suture correction in penetrating keratoplasty. Ophthalmology 1995;92:133-8.

8 Nabors G, Vander Zwang R, Van Meter WS, et al. Suture adjustment for post keratoplasty astigmatism. $\mathcal{f}$ Cataract Refract Surg 1991;17:547-50.

9 Yue-Kong-Au, Mahjoub SB, Hart JC. Suture patterns and corneal graft rotation in the cadaver eye. Ophthalmic Surg 1990;8:58-61.

10 Holladay JT, Thomas V, Cravy MD, et al. Calculating the surgically induced refractive change following ocular surgery. F Cataract Refract Surg 1992;18:429-42.

11 Cornea, Refractive Surgery and Contact Lens. Transactions of the New Orleans Academy of Ophthalmology. New Orleans: Raven Press, 1987.

12 Mader TH, Yuan R, Lynn MJ, et al. Changes in keratometric astigmatism after suture removal more than one year ric astigmatism after suture removal more
after PK. Ophthalmology 1993;100:119-27.

13 Hovding G. Suture adjustment in PK. Acta Ophthalmol (Copenh) 1994;72:246-52. 